\title{
Endocardial Fibro-elastosis, Mitral Incompetence, and Coarctation of Abdominal Aorta
}

\author{
A Report of Three Sibs \\ K. A. HALLIDIE-SMITH AND E. G. J. OLSEN* \\ From the Departments of Medicine (Clinical Cardiology) and Morbid Anatomy, \\ Royal Postgraduate Medical School, London W.12
}

Congenital mitral incompetence has been only rarely reported as an isolated lesion (Miller, Brown, and Swan, 1964), but may occur as a result of endocardial fibro-elastosis, which is also commonly associated with other anatomical abnormalities, of which coarctation of the aorta is one. The association of congenital mitral incompetence and coarctation of the abdominal aorta has not been reported previously, so we are presenting a family of 3 sibs who had this association of defects. The pathological findings are given in some detail, and the pathology of endocardial fibro-elastosis is reviewed.

\section{CASE REPORTS}

The 3 children were the offspring of young, healthy, non-consanguineous British parents. There was no known family history of congenital heart disease or other congenital abnormalities, going back two generations.

The first child born to these parents was a full-term, stillborn breech (male), weighing 1984 g. (5 lb. 6 oz.). The cause of death was unknown. Necropsy did not reveal any gross abnormality of the heart, and no specific mention was made of the valves or aorta.

Case 1. The first of the three children was born in May 1957. She was a full-term breech delivery weighing $3883 \mathrm{~g}$. ( $8 \mathrm{lb} .9 \mathrm{oz}$.). A heart murmur, thought to be functional, was first heard at the age of 3 months when she developed bronchitis. She was re-examined at the age of 3 years when she developed measles, and was referred to Dr. Mary Wilmers (King's College Hospital) who diagnosed mitral incompetence.

She was first seen at Hammersmith Hospital at the age of 5 years, with a history of shortness of breath on

Received April 27, 1968.

$\star$ Supported by a grant from the British Heart Foundation. Requests for reprints should be addressed to E. G. J. Olsen. exertion for 1 year. She appeared a little blue at times, particularly in cold weather.

On examination, she was of poor general physique and of average height, but underweight, with bulging chest, particularly on the left side, and a cyanotic tinge (Fig. 1). The cardiac impulse suggested biventricular hypertrophy. The second sound moved normally with respiration and the pulmonary component was accentuated. There was an ejection systolic murmur maximal at the pulmonary area and a high-pitched pansystolic murmur, maximal at the apex and radiating to the axilla. After the third heart sound there was a moderately loud decrescendo diastolic murmur.

Investigations. The ausculatory findings were confirmed by the phonocardiogram (Fig. 2). The electrocardiogram showed evidence of biventricular hypertrophy. The chest radiograph (Fig. 3a and b) showed generalized cardiomegaly, with left atrial enlargement and distended upper zone veins. Right heart catheterization (Table) confirmed that she had a raised left atrial pressure and pulmonary hypertension. Left ventricular angiography (Fig. 4) showed an enlarged left ventricular cavity and regurgitation of contrast from the left ventricle into a large left atrium. Both the left atrium and the ventricle appeared to contract well.

Diagnosis. A diagnosis of congenital mitral incompetence with pulmonary hypertension was made. The possibility of mitral valve replacement or repair was discussed, but at that time it was felt that it should not be recommended for such a young child.

Progress. She continued to deteriorate, and by 1965 she was in chronic heart failure, with a further increase in heart size, hepatomegaly, oedema of the feet, raised jugular venous pressure, and signs of tricuspid incompetence. She also had a chronic iron-deficiency anae850 

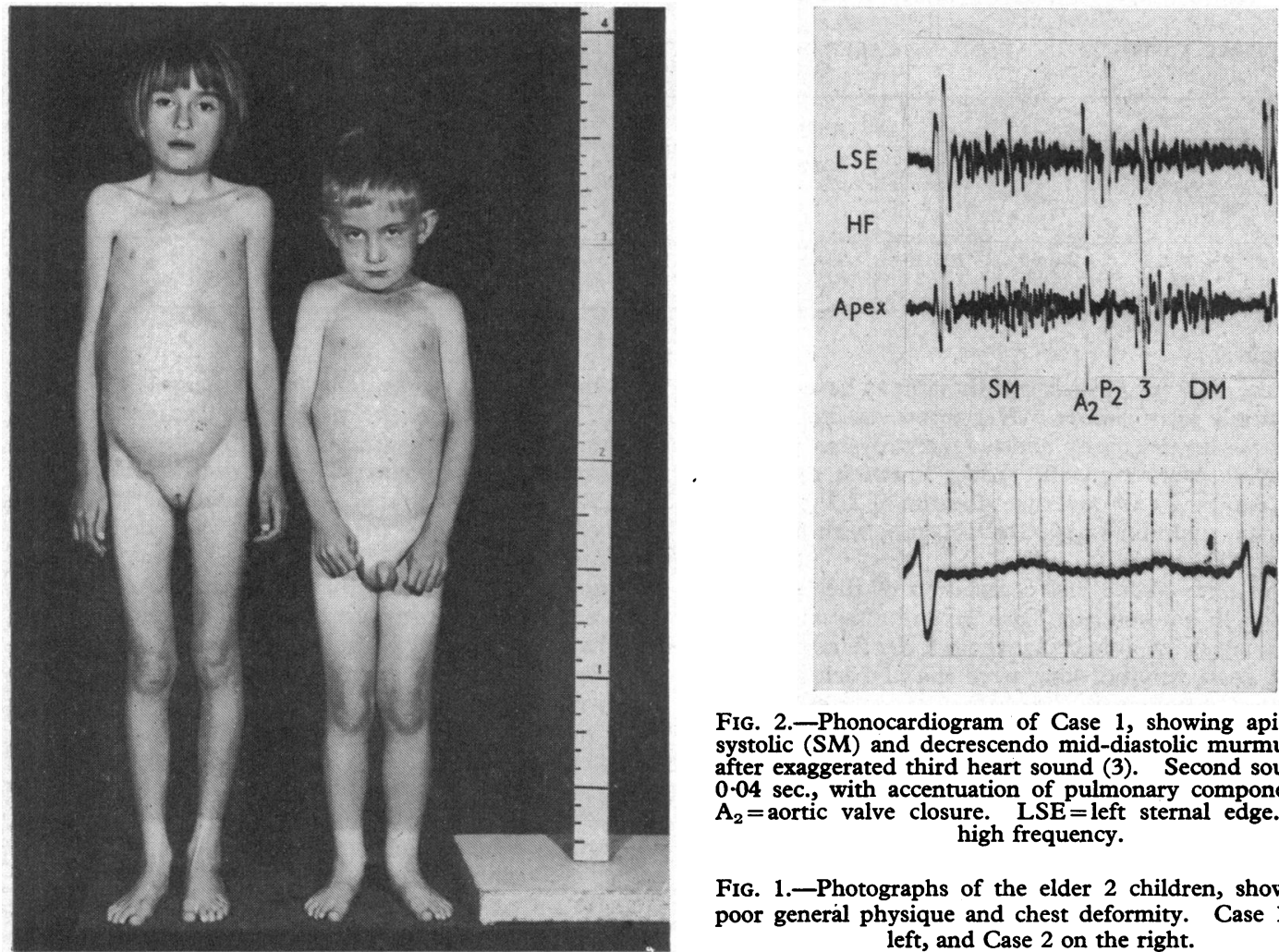

FIG. 2.-Phonocardiogram of Case 1, showing apical pansystolic (SM) and decrescendo mid-diastolic murmur (DM) after exaggerated third heart sound (3). Second sound split 0.04 sec., with accentuation of pulmonary component $\left(\mathbf{P}_{2}\right)$. $A_{2}=$ aortic valve closure. $L S E=$ left sternal edge. $H F=$ high frequency.

Fig. 1.-Photographs of the elder 2 children, showing the poor general physique and chest deformity. Case 1 on the left, and Case 2 on the right.

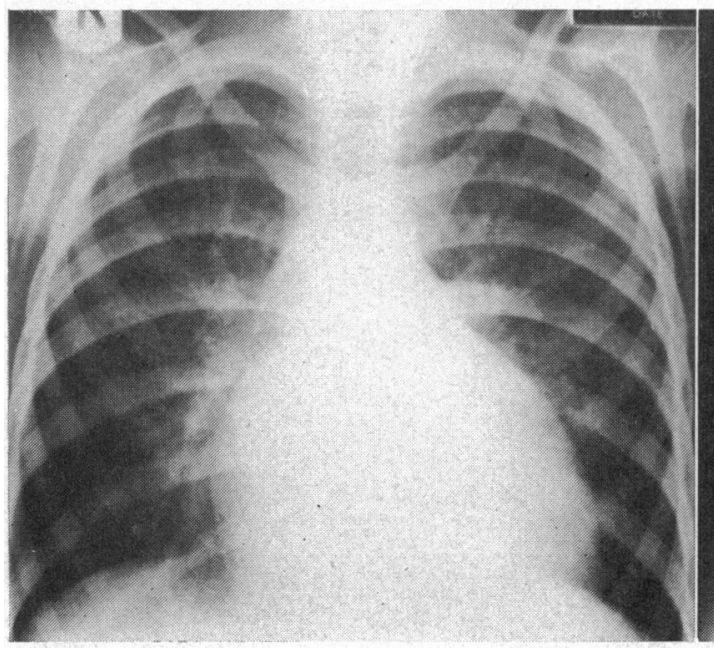

(a)

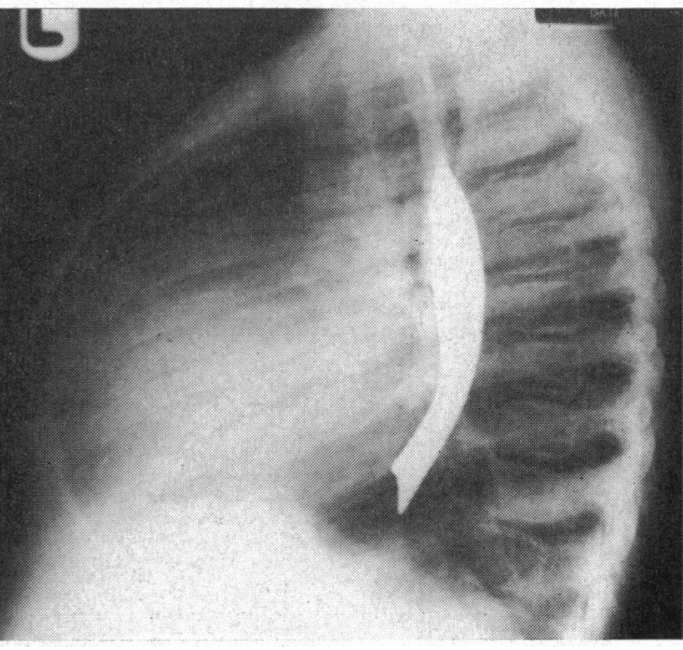

(b)

Fig. 3.-Case 1 -chest $x$-ray at the age of seven. (a) Postero-anterior film showing generalized cardiomegaly, left atrial enlargement, and distension of upper lobe veins. (b) Lateral film showing prominent sternum, right ventricular enlargement.

Chest $x$-ray of Case 2 was normal at 3 years, but at 7 years showed a bowed sternum, generalized cardiomegaly, some left atrial enlargement, and distended upper lobe veins. Chest $x$-ray of Case 3 showed a heart size at the upper limits of normal, no left atrial enlargement, and normal lung fields. 
TABLE

CARDIAC CATHETERIZATION IN CASES 1 AND 2 WITH MITRAL INCOMPETENCE AND COARCTATION OF ABDOMINAL AORTA

\begin{tabular}{|c|c|c|c|c|c|c|c|c|c|c|c|c|}
\hline \multirow[b]{2}{*}{$\begin{array}{l}\text { Case } \\
\text { No. }\end{array}$} & \multirow[b]{2}{*}{$\begin{array}{c}\text { Age } \\
\text { (yr.) } \\
.\end{array}$} & \multicolumn{8}{|c|}{ Pressures (mm. Hg) } & \multirow[b]{2}{*}{$\begin{array}{c}\text { Arterial } \\
\text { O }^{2} \text { sat. } \\
(\%)\end{array}$} & \multirow[b]{2}{*}{$\begin{array}{c}\text { Cardiac } \\
\text { index } \\
(1 . / \mathrm{min} . / \\
\left.\mathrm{m.} .^{2}\right)\end{array}$} & \multirow[b]{2}{*}{$\begin{array}{l}\text { Pulm. } \\
\text { arteriolar } \\
\text { resistance }\end{array}$} \\
\hline & & $\begin{array}{l}\text { Pulm. } \\
\text { artery }\end{array}$ & Aorta & $\begin{array}{c}\text { Left } \\
\text { ventricle }\end{array}$ & $\begin{array}{c}\text { Right } \\
\text { ventricle }\end{array}$ & $\begin{array}{c}\text { Mean } \\
\text { indirect } \\
\text { left } \\
\text { atrial }\end{array}$ & $\begin{array}{l}\text { Mean } \\
\text { right } \\
\text { atrial }\end{array}$ & $\begin{array}{c}\text { Brachial } \\
\text { artery } \\
1\end{array}$ & $\begin{array}{c}\text { Femoral } \\
\text { artery }\end{array}$ & & & \\
\hline $\begin{array}{l}1 \\
2\end{array}$ & $\begin{array}{l}5 \\
6\end{array}$ & $\begin{array}{l}75 / 25 \\
60 / 12\end{array}$ & $\begin{array}{l}150 / 65 \\
175 / 50\end{array}$ & $\begin{array}{l}160 / 18 \\
175 / 27\end{array}$ & $\begin{array}{l}75 / 0 / 4 \\
62 / 0 / 7\end{array}$ & $\begin{array}{l}19 \\
32\end{array}$ & $\begin{array}{l}5 \\
3\end{array}$ & $\begin{array}{l}150 / 45 \\
149 / 50\end{array}$ & $1 \overline{12 / 62}$ & $\begin{array}{l}88 \\
94\end{array}$ & $\begin{array}{l}3 \cdot 8 \\
3 \cdot 5\end{array}$ & $\begin{array}{l}8 \\
1 \cdot 7\end{array}$ \\
\hline
\end{tabular}

was $60 \mathrm{mg}$./100 ml., which was thought to be consistent with chronic heart failure. Her urine was normal and intravenous pyelography showed normal-sized kidneys which were excreting well. Liver function tests were normal except for a low serum albumin of $2 \cdot 2 \mathrm{~g} . / 100 \mathrm{ml}$. The serum globulin was $3.3 \mathrm{~g} . / 100 \mathrm{ml}$., with a normal electrophoretic strip.

At this time abdominal coarctation of the aorta was diagnosed in her brother (Case 2), and after careful reexamination it was noted that though her femoral pulses were of good volume, they were slightly delayed. All the foot pulses were present, the blood pressure was $105 / 33 \mathrm{~mm}$. $\mathrm{Hg}$ in both arms and $80 / 40 \mathrm{~mm}$. $\mathrm{Hg}$ in both legs. A translumbar aortogram showed a diffusely narrow segment of aorta, starting just below the level of the renal arteries which appeared normal.

In view of her deterioration, mitral valve repair or replacement was now advised. Surgical treatment for the abdominal coarctation was not feasible, and her hypertension was not of sufficient severity to warrant medical treatment.
Operation. This was done in February 1965 by Mr. W. P. Cleland, with the patient on cardiopulmonary bypass. The mitral valve cusp tissue appeared to be deficient and the remnants were thickened. The orifice was $3 \times 1 \mathrm{~cm}$. The chordae appeared to be almost totally absent, with the papillary muscle inserted directly into the cusps. The aortic cusp was advanced by inserting a $5 \times 3 \mathrm{~cm}$. ellipse of pericardium into its base, and the repair appeared to be competent. There was, however, no relief of pulmonary hypertension, and she died less than 12 hours later with signs of a progressively falling cardiac output.

Necropsy findings. The heart weighed $200 \mathrm{~g}$. The organ was grossly hypertrophied and dilated. The right ventricle (conus) measured $6 \mathrm{~mm}$. and the left ventricle $11 \mathrm{~mm}$. Left and right atria measured 3 and $3.5 \mathrm{~mm}$., respectively, and the foramen ovale was closed. Striking changes were seen in the endocardium which was particularly thick in the atrium, being over $1 \mathrm{~mm}$. in thickness. This thickened white tissue extended from the

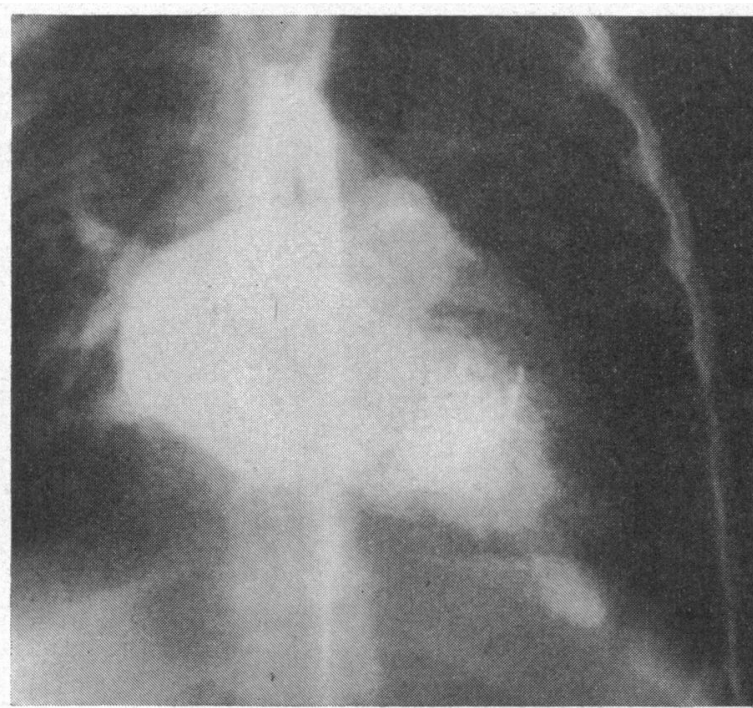

(a)

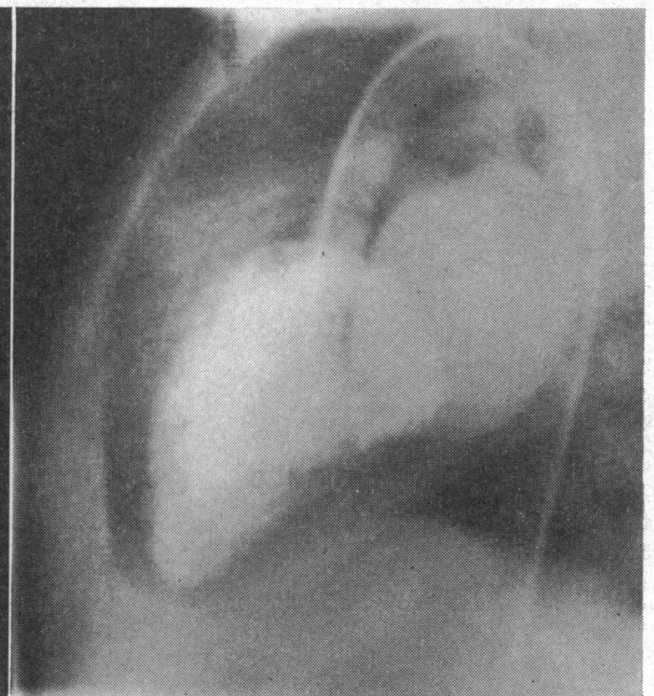

(b)

Fig. 4.-Case 1-left ventricular angiocardiogram. (a) Antero-posterior view, and (b) lateral view, showing regurgitation of contrast material into the enlarged left atrium.

The left ventricular angiocardiogram of Case 2 was almost identical, though the left atrium was smaller. 


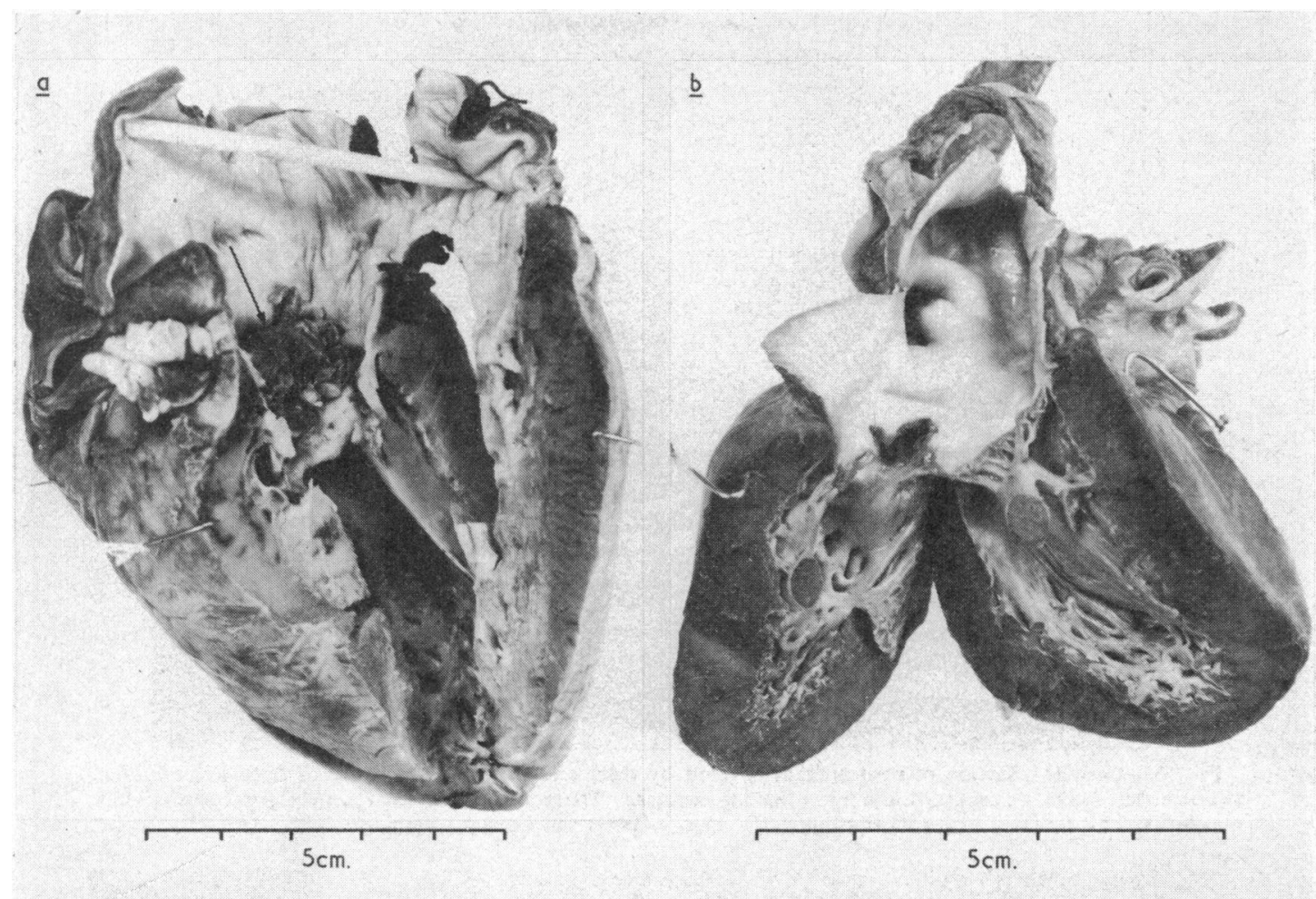

FIG. 5-(a). Case 1. Left atrium and left ventricle opened to show the thick endocardium of the left atrium embedding the mitral valve and chordae tendineae. The irregular thick area (arrow) is the pericardial patch. (b) Case 3. Left atrium and left ventricle. Note the thick mitral valve covered by white tissue continuous with the atrium. Note also minor endocardial thickening in the outflow tract and at the apex. The changes in this heart are less severe than in the heart of Case 1.

endocardium of the left atrium over the posterior cusp of the mitral valve and over chordae tendineae, on to the posterior papillary muscle. Some of the embedded chordae tendineae could just be identified (Fig. 5a). Endocardial thickening was also seen in the apex and at the left ventricular outflow tract; it was particularly marked just beneath the aortic valve. The right ventricle showed some endocardial thickening, particularly overlying the papillary muscle of the conus. The mitral valve ring measured $71 \mathrm{~mm}$. The anterior mitral valve cusp showed the pericardial patch inserted, which measured $20 \times 25 \mathrm{~mm}$. (ballooning slightly), the centre measuring about $9 \mathrm{~mm}$. above the mitral valve ring. All sutures were intact. The posterior valve cusp showed, on its atrial surface, endocardial thickening, but otherwise no abnormalities. The tricuspid valve $(72 \mathrm{~mm}$.), pulmonary valve $(44 \mathrm{~mm}$.), and aortic valve $(29 \mathrm{~mm}$.) showed no abnormalities. The pericardium was normal.

Histology. All sections examined were stained by haematoxylin and eosin and by Weigert's elastic van Gieson stains. The endocardium was grossly thickened and consisted of fibro-elastic tissue. The elastic fibres were fine and fibrillar towards the cardiac lumen, but assumed a coarser, more regular configuration in the deeper layers. The fibres were regularly arranged (Fig. 6). Bands of fibro-elastic tissue extended from this thickened endocardium into the underlying myocardium for about one-third of the wall thickness. There was no increase in vascularity or inflammatory cells. The posterior leaflet of the mitral valve showed gross distortion of normal architecture and gross thickening. The thickening consisted predominantly of hyalinized collagen tissue and areas of fibro-elastic tissue. There was also no increased vascularity and there were no inflammatory cells. The myocardium showed hypertrophy but no other abnormalities, and the epicardium was within the normal limits.

Diagnosis: The macroscopical as well as the histological appearances were consistent with the diagnosis of congenital endocardial fibro-elastosis.

The aorta pursued a normal course, but just below the renal arteries the lumen narrowed abruptly and continued as a narrowed channel to the bifurcation. The intima showed some slight thickening at the point of 


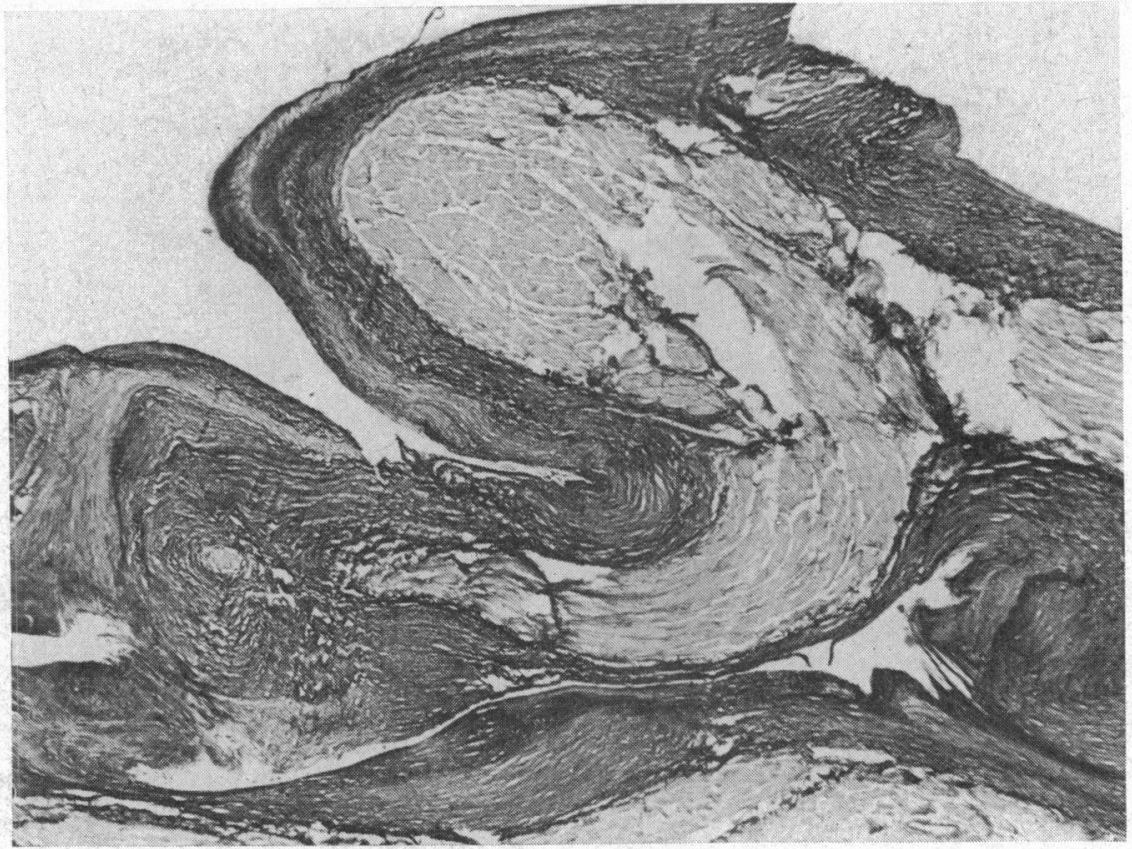

FIG. 6.-Case 1. Section of myocardium covered by thick endocardium consisting of fibro-elastic tissue. The elastic fibres are arranged in a fairly regular manner. There is no increased vascularity or inflammatory cell infiltrate. (Weigert's elastic van Gieson. $\times 40$.)

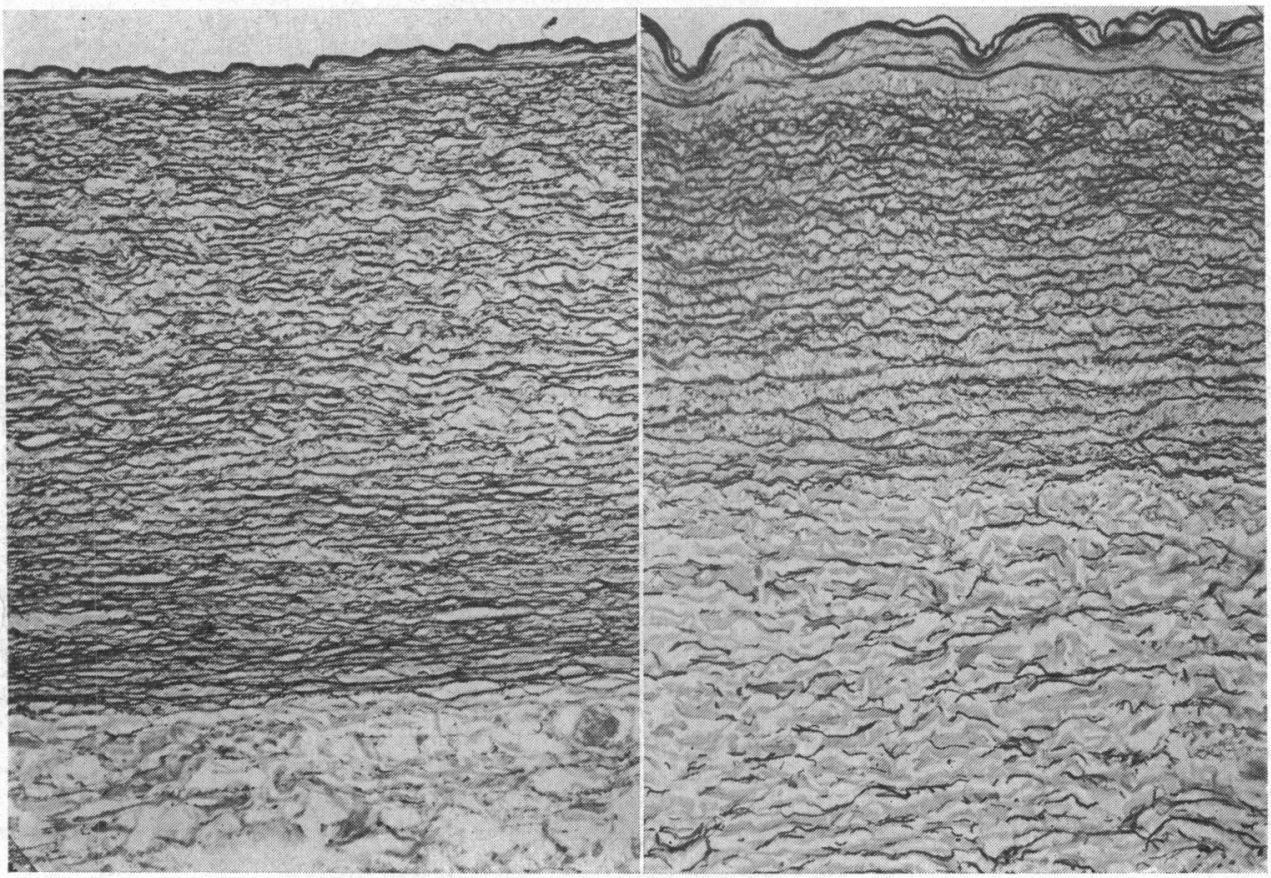

(a)

(b)

FIG. 7.-Case 1. (a) Section of the abdominal aorta just proximal to renal vessels, and (b) abdominal aorta just distal to renal vessels. Note the thickness of the media: about one-third of the total thickness. (van Gieson. $\times 100$.) 
initial narrowing, and a very slight increase in fibrous tissue was also noted. Histology confirmed mild intimal thickening consisting of fibrous elastic tissue, the media was thickened, and the elastic tissue was grossly reduced (Fig. 7a and b). The serosa showed a slight increase in fibrous tissue just below the renal vessels, and also showed a slight increase in capillaries and lymphatics; but in the rest of the sections examined the serosa was normal. There was no evidence of past or present inflammation.

The only other abnormal necropsy finding was congestion of the abdominal organs.

Case 2. The second child was born in March 1959. He was a full-term vertex delivery and weighed $2721 \mathrm{~g}$. (6 lb.). He was referred to Dr. Wilmers at the age of 2 years for a routine examination on account of his sister's cardiac lesion, and was diagnosed as having mitral incompetence. He was first seen at Hammersmith Hospital at 3 years, at which time he was asymptomatic.

On examination, he was of average height but underweight, and had some bulging of his chest, particularly on the left side. He was strikingly like his sister in facial appearance and general physique (Fig. 1), but unlike either parent. His cardiac impulse was normal, as were his heart sounds, except for a strikingly loud third heart sound. He had a pansystolic murmur best heard at the apex and radiating to the axilla. Both electrocardiogram and chest radiograph were normal.

Progress and investigations. Between 4 and 5 years he slowly deteriorated, becoming short of breath on exertion and easily tired. His physical signs suggested that the mitral incompetence was becoming more severe, and that he had also developed pulmonary hypertension and tricuspid incompetence. At that time the cardiovascular findings were almost identical with those described in his sister at the age of 5 years. ${ }^{-H e}$ later progressed to chronic heart failure, with oedema of the feet, raised jugular venous pressure, and hepatomegaly. His chest radiograph showed an increase in heart size. His electrocardiogram showed biventricular hypertrophy. At this time, also, he developed a chronic iron-deficiency anaemia. Right and left heart catheterization (Table) and left ventricular angiocardiography confirmed the diagnosis of severe mitral incompetence with pulmonary hypertension. There was regurgitation of contrast material into an only moderately enlarged, but immobile, left atrium. The left ventricle contracted well, but the cavity was enlarged.

His electrolytes, urine, and intravenous pyelogram were normal, but the blood urea of $60 \mathrm{mg}$. $/ 100 \mathrm{ml}$. was thought to be consistent with chronic heart failure. Liver function tests including serum electrophoresis were normal.

On this admission, it was noted that the femoral pulses, though of good volume, were delayed, and differential blood pressures were $155 / 70 \mathrm{~mm}$. $\mathrm{Hg}$ in both arms, and $80 / 40 \mathrm{~mm}$. $\mathrm{Hg}$ in both legs. The foot pulses were all present. A soft abdominal bruit was noted. An aortogram, using the retrograde Seldinger technique via the right femoral artery, showed a normal aortic arch, but a diffuse segment of narrowing of the abdominal aorta starting at the level of the renal arteries which appeared normal (Fig. 8), the appearance being identical to that of his sister.

He thus presented with an identical picture to that of his sister. It was felt that his considerable systemic hypertension was important in increasing the mitral incompetence, and so was eventually controlled by methyldopa. It was thought that his mitral incompetence would be amenable to operation, but after his sister's death the parents were opposed to an operation. $\mathrm{He}$ is still alive, but remains in chronic heart failure with frequent episodes of acute pulmonary oedema.

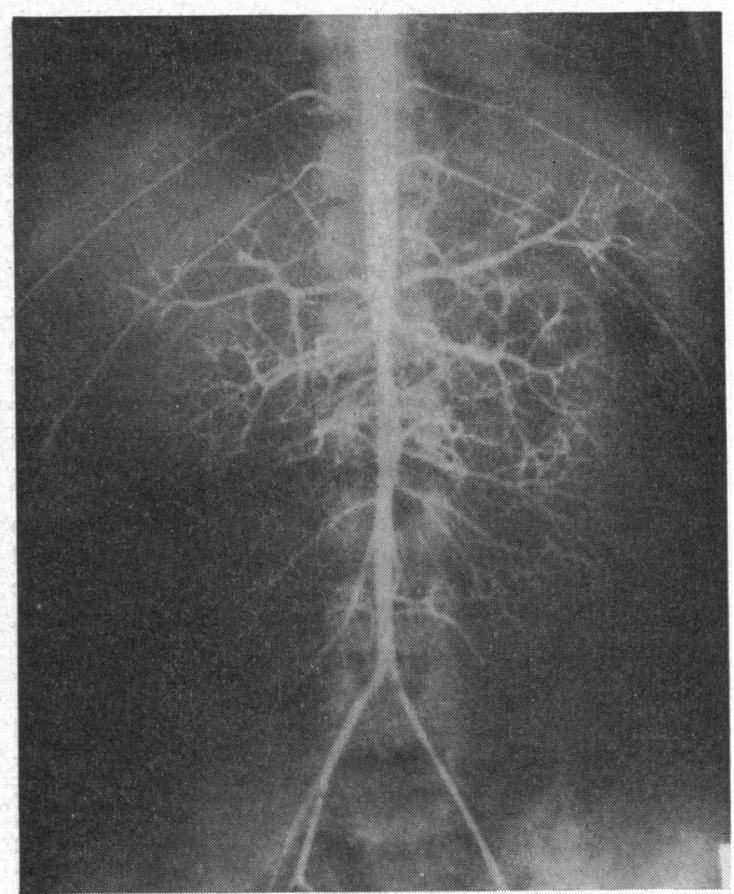

FIG. 8.-Case 2. Retrograde aortogram with Kifa catheter in situ, showing narrowing of lower segment of abdominal aorta, starting just below the level of the renal arteries. The retrograde aortogram of Case 1 showed an identical picture.

Case 3. The third child was a normal full-term vertex delivery, born in April 1966 and weighing $2636 \mathrm{~g}$. (5 lb. $13 \mathrm{oz}$.). He was mildly jaundiced from the third to the seventh day. He was seen regularly at the hospital's neonatal follow-up clinic, but no abnormality was detected. He remained well until the age of 7 months when he developed bronchitis which responded to treatment but was followed by diarrhoea, and later by swelling of the abdomen. He was admitted to Hammersmith Hospital in December 1966.

On admission he looked a chronically sick pale infant with a facial appearance similar to his, sibs. His abdomen was distended with free fluid, and there were 
dilated superficial abdominal veins. There was firm enlargement of his liver $4 \mathrm{~cm}$. below the costal margin, his spleen was enlarged $1 \mathrm{~cm}$. below the costal margin, and there was a soft abdominal bruit. His peripheral arterial pulses were present, but the femoral arterial pulses were slightly weaker than his brachial pulse and were delayed. The blood pressures were $130 / 80 \mathrm{~mm}$. $\mathrm{Hg}$ in both arms, and $80 / 40 \mathrm{~mm}$. $\mathrm{Hg}$ in both legs. His jugular venous pressure was not raised and his cardiac impulse was normal. There was a soft apical pansystolic murmur and a third heart sound, and short middiastolic murmur. The second heart sound split normally and the pulmonary component was not accentuated.

The cardiovascular findings suggested that, like his sister and brother, he had congenital mitral incompetence and coarctation of the abdominal aorta. The clinical impression that the mitral incompetence was mild was borne out by the chest radiograph and electrocardiogram, which were assessed as normal. However, unlike his sibs, he apparently had a systemic disease in addition to, or connected with, his cardiovascular disease, and further investigations were carried out, necessarily limited by the size of the baby and his serious condition.

$\mathrm{He}$ was found to be anaemic (Hb $8.5 \mathrm{~g} . / 100 \mathrm{ml}$.), and this was shown to be due to iron deficiency. No renal lesion was detected and his electrolytes remained normal until shortly before his death, when the changes could be accounted for by an intensive diuretic regimen. Acute and chronic infections, intestinal parasites, coeliac disease, and fibrocystic disease as causes for the diarrhoea were excluded as far as possible, and it was concluded that the frequent loose stools must be secondary to the ascites. Investigations also excluded Hurler's syndrome, galactosaemia, and congenital syphilis.

Routine liver function tests showed a normal serum bilirubin and alkaline phosphatase. The isocitrate dehydrogenase was slightly raised (9-18 units) and the bromsulphalein retention was 21 per cent in 45 minutes (normal less than 5\%). The serum albumin was reduced to $2.4 \mathrm{~g} . / 100 \mathrm{ml}$., with a globulin of $2.5 \mathrm{~g} . / 100 \mathrm{ml}$. and a normal electrophoretic strip. The ascitic fluid was straw coloured, with a protein content of $1 \mathrm{~g} . / 100 \mathrm{ml}$., and was sterile on culture. There was no evidence of oesophageal varices and his stools were negative for occult blood. Chromosome studies were carried out on the baby, his sibs, and both parents, with negative findings.

Progress. The baby steadily deteriorated. His ascites rapidly reaccumulated and he required frequent paracentesis. He became increasingly wasted and shortly before his death in February 1967 he had a haematemesis.

Diagnosis. The final clinical diagnosis was cirrhosis of the liver with portal hypertension, and congenital mitral incompetence and abdominal coarctation of the aorta. An over-all diagnosis could not be made.
Necropsy findings. The heart weighed $44 \mathrm{~g}$. There was hypertrophy of both left and right ventricles, but no obvious dilatations. The left ventricle measured 10 $\mathrm{mm}$.; the right ventricle measured $3 \mathrm{~mm}$. in thickness. The endocardium of the left atrium was grossly thickened, and this extended to involve the cusps of the mitral valve. Both anterior and posterior leaflets were involved (Fig. 5b). The chordae tendineae were also thickened and shortened, and fusion of some of them had occurred. The thickened endocardium was also apparent in the outflow tract of the left ventricle and the apex. In addition, endocardial thickening was present in the right ventricular outflow tract and around the posterior papillary muscle. The mitral valve measured $30 \mathrm{~mm}$., the aortic valve $22 \mathrm{~mm}$.; both these were at the lower limit of normal. The tricuspid valve and the pulmonary valve measured 43 and $29 \mathrm{~mm}$., respectively.

The aorta showed considerable variation in calibre throughout its course, but above the renal vessels it was normal. Below these vessels, the diameter of the aorta was greatly reduced and continued greatly narrowed to the bifurcation. The macroscopical appearances were similar to those of Case 1. No other cardiovascular abnormalities were present.

Histology. The heart and aorta showed similar findings to those in Case 1. There was also no evidence of past or present inflammation.

The liver showed patchy fibrosis throughout the organ and a mild inflammatory infiltrate in the portal tract. The liver plates were thickened, but this was a normal appearance at this age. The appearances of the liver were consistent with the Budd-Chiari syndrome.

In conclusion, the changes in the endocardium were similar to, though milder than, those of Case 1 , and were compatible with congenital fibro-elastosis. There was also coarctation of the abdominal aorta starting at the level of the renal arteries.

\section{Discussion}

The incidence of congenital mitral incompetence is difficult to assess. Isolated mitral incompetence, due to an anatomical defect, seems to be rare (Miller et al., 1964; Berghuis et al., 1964). Before 1964, only 20 cases had been reported. Flege, Vlad, and Ehrenhaft (1967) described 9 patients who had isolated congenital mitral incompetence, in whom valve repair was possible. Reported cases have had abnormalities of the valve tissue, with loss of cusp tissue, clefts or fenestration, and abnormalities of the chordae which have been abnormally short, long, accessory, or have had anomalous insertion. Dilatation of the valve ring is described, but it is doubtful whether it ever occurs as a primary abnormality.

Endocardial fibro-elastosis may involve the left atrium and ventricle, and the papillary muscle, chordae, and cusps may become involved in the 
process, with resultant mitral incompetence (Lambert, Shumway, and Terplan, 1953; Edwards and Burchell, 1958; Hudson, 1965). Mitral or aortic valve deformities occur in 35-53 per cent of cases of endocardial fibro-elastosis (Dennis, Hansen, and Corpening, 1953), the pulmonary and tricuspid valves being rarely affected.

Congenital mitral incompetence is commonly associated with other anatomical defects. It may, of course, be part of an atrioventricular canal defect, or can occur in association with corrected transposition of the great arteries, ventricular septal defect, ostium secundum atrial septal defect, supravalvar aortic stenosis, aortic valve stenosis, anomalous coronary artery, and coarctation of the aorta.

The 3 children described had the same congenital cardiovascular abnormalities: mitral incompetence and coarctation of the abdominal aorta. The mitral incompetence was only mild in infancy, but deterioration took place between the ages of 3 and 4 years in the 2 older children. It is conceivable that this process was a continuous one, and that the secondary changes in the mitral valve were responsible for the clinical deterioration. In 2 of the sibs we have pathological proof of endocardial fibro-elastosis involving the left ventricle and atrium, with involvement of the papillary muscle, chordae, and valve cusps, accounting for the mitral incompetence. Though the second sib had a smaller left atrium than his sister, he had a higher left atrial pressure and episodes of acute pulmonary oedema. This suggests that his left atrium might have been more severely affected by endocardial fibro-elastosis, thus rendering it less compliant so that blood regurgitated directly to the pulmonary veins.

In all 3 children, there was diffuse narrowing of the abdominal aorta, beginning just below the level of the renal arteries, with no evidence of a local constriction.

A familial incidence of endocardial fibro-elastosis has been reported by Sellers, Keith, and Manning $(1964)$, and similar endocardial involvement has been described in 2 sibs by Rosahn (1955). The identical cardiovascular findings in our 3 children suggest a hereditary defect, but no other members of the family are known to have been affected. The children resembled one another, rather than their parents, but they did not represent a recognizable syndrome and no chromosomal abnormalities were detected.

Congenital endocardial fibro-elastosis has appeared under a variety of synonyms such as foetal endocarditis, congenital idiopathic hypertrophy of the heart, foetal endomyocarditis, endocardial sclerosis, and many others. It has been subdivided into two groups, that of congenital fibro-elastosis of infants and that of adults. In addition, dilated and contracted types have been recognized (Edwards, 1960). The lesion must be distinguished from acquired disease, in particular, rheumatic carditis. In both, there is endocardial thickening and the chordae tendineae are shortened and thickened, but in rheumatic carditis the endocardial thickening, particularly that of the left ventricle, is roughened (McCallam patch), whereas that in primary elastosis is smooth and porcelain-like. In addition, when the thickened endocardium is directly continuous over the posterior leaflet of the mitral valve and embeds this, as well as the chordae tendineae, primary fibro-elastosis is likely to be present. Regular bands of elastic tissue embedded in collagen tissue are present in cases of primary fibro-elastosis, without any evidence of inflammation or increased vascularity (which might reflect previous infection); whereas in rheumatic carditis increased vascularity can usually be found. The distribution of the endocardial thickening may be helpful in distinguishing various types of endocardial thickening, including that due to secondary thickening caused by the mitral valve incompetence. This again may also be differentiated histologically. The appearance of the endocardium in various conditions has been described by Davies (1963).

In the cases under discussion, the histological appearances were consistent with primary fibroelastosis, but no components of normal endocardium were seen. Occasionally, smooth muscle hypertrophy can be identified in the thickened parts of the endocardium (Gowing, 1953).

The aetiology of endocardial fibro-elastosis is not known. At one time it was believed to be due to foetal endocarditis or to prenatal virus infection, but there is some evidence that obstruction of the lymphatics in the heart forms lesions similar to primary fibro-elastosis (Miller, Pick, and Katz, 1963). It is believed that both the infantile and adolescent types are of a similar nature, the latter occurring in a much milder form.

Coarctation of the aorta commonly occurs in the upper part of the aorta either proximally or distally to the ligamentum arteriosum and ductus arteriosus. Coarctation of the abdominal aorta is rare. Pyörälä et al. (1960) reviewed the 27 published-cases, including his own. D'Abreu, Rob, and Vollmar (1959) classified coarctation of the abdominal aorta into segmentary and hypoplastic types, further subdivided into supra-, inter-, and infra-renal types.

Our patients fit into the hypoplastic and infrarenal group, with little pathological macroscopical change and no strictures or diaphragmatic deformities. Histological changes were confined to intimal 
thickening and thinning of the media, with a decrease in elastic tissue and some minor thickening of the adventitia. Slightly increased vascularity of the adventitia below the renal arteries was noted in Case 1, but in none of the numerous sections examined were there any inflammatory changes such as those described by Sen et al. (1962, 1963). Finally, the Budd-Chiari syndrome in Case 3 was considered to be coincidental.

\section{SUMMARY}

A family of 3 children with congenital mitral incompetence and abdominal coarctation of the aorta is described. The mitral incompetence was demonstrated as being due to endocardial fibro-elastosis in 2 of them, and is the presumed aetiology in the third.

The children were similar in appearance and in their cardiovascular abnormalities. The youngest child also had portal vein thrombosis and died as a result of portal hypertension; this was thought to be an unassociated problem.

The mitral incompetence was mild in infancy in all 3 children, and deterioration took place between 3 and 4 years of age. Mitral valve repair was carried out in the eldest child, and though she did not survive operation, a competent valve was obtained.

Coarctation of the abdominal aorta is a rare anomaly. It was present at an identical site in all 3 children, starting just below the origin of the renal arteries. Though congenital mitral incompetence in association with other cardiovascular abnormalities has frequently been described, its combination with coarctation of the abdominal aorta has not been previously reported.

The pathological changes are described in detail, and the pathology of endocardial fibro-elastosis is reviewed.

The children were under the care of Professor J. F. Goodwin, and we should like to thank him for his helpful criticism and advice. We should also like to thank Professor J. P. M. Tizard for his advice on the investigation and management of the third child and
Dr. M. Wilmers for referring the family to us. We are grateful to Professor R. E. Steiner for radiological advice, to the Department of Medical Illustration, and to Dr. J. Wigglesworth who kindly allowed us to use the necropsy data on the third child.

\section{REFERENCES}

Berghuis, J., Kirklin, J. W., Edwards, J. E., and Titus, J. L. (1964). The surgical anatomy of isolated congenital mitral insufficiency. F. thorac. cardiovasc. Surg., 47, 791.

D'Abreu, A. L., Rob, C. G., and Vollmar, J. F. (1959). Die Coarctatio aortae abdominalis. Langenbecks Arch. klin Chir., 290, 521.

Davies, J. N. P. (1963). Pathology and pathogenesis of endocardial disease. Cardiologia (Basel), 42, 161.

Dennis, J. L., Hansen, A. E., and Corpening, T. N. (1953). Endocardial fibroelastosis. Pediatrics, 12, 130.

Edwards, J. E. (1960). Pathology of the Heart, 2nd ed., p. 419. Ed. by S. E. Gould. Charles C. Thomas, Springfield, Illinois.

-, and Burchell, H. B. (1958). Pathologic anatomy of mitral insufficiency. Mayo Clin. Proc., 33, 497.

Flege, J. B., Vlad, P., and Ehrenhaft, J. L. (1967). Congenital mitral incompetence. $\mathcal{f}$. thorac. cardiovasc. Surg., 53, 138.

Gowing, N. F. C. (1953). Congenital fibroelastosis of the endocardium. F. Path. Bact., 65, 13.

Hudson, R. E. B. (1965). Cardiovascular Pathology, Vol. 2, p. 1963. Edward Arnold, London.

Lambert, E. C., Shumway, C. N., and Terplan, K. (1953). Clinical diagnosis of endocardial fibrosis. Analysis of literature with report of four new cases. Pediatrics, 11, 255.

Miller, A. J., Pick, R., and Katz, L. N. (1963). Ventricular endomyocardial changes after impairment of cardiac lymph flow in dogs. Brit. Heart f., 25, 182.

Miller, G. A. H., Brown, R., and Swan, H. J. C. (1964). Isolated congenital mitral insufficiency with particular reference to left heart volumes. Circulation, 29, 356.

Pyörälä, K., Heinonen, O., Koskelo, P., and Heikel, P. (1960). Coarctation of the abdominal aorta. Review of 27 cases. Amer. F. Cardiol., 6, 650.

Rosahn, P. D. (1955). Endocardial fibroelastosis: old and new concepts. Bull. N.Y. Acad. Med., 31, 453.

Sellers, F. J., Keith, J. D., and Manning, J. A. (1964). Diagnosis of primary endocardial fibro-elastosis. Circulation, 29, 49.

Sen, P. K., Kinare, S. G., Engineer, S. D., and Parulkar, G. B. (1963). The middle aortic syndrome. Brit. Heart f., 25, 610 .

$\longrightarrow,-$, Kulkarni, T. P., and Parulkar, G. B. (1962). Stenosing aortitis of unknown aetiology. Surgery, 51, 317. 